\title{
Matrix metalloproteinases, tissue inhibitors of MMPs and TACE in experimental cerebral malaria
}

\author{
Philippe E Van den Steen ${ }^{1}$, Ilse Van Aelst ${ }^{1}$, Sofie Starckx ${ }^{1}$, Klaus Maskos ${ }^{2}$, \\ Ghislain Opdenakker ${ }^{1}$ and Axel Pagenstecher ${ }^{3}$ \\ ${ }^{1}$ Laboratory of Immunobiology, Rega Institute, University of Leuven, Leuven, Belgium; ${ }^{2}$ Abteilung \\ Strukturforschung, Max-Planck-Institut für Biochemie, Martinsried, Germany and ${ }^{3}$ Department of \\ Neuropathology, University of Marburg, Marburg, Germany
}

\begin{abstract}
Cerebral malaria (CM) is a life-threatening disorder and a major medical problem in developing countries. It is caused by the sequestration of malaria-infected erythrocytes onto brain endothelia, followed by blood-brain barrier (BBB) damage and neurological deficit. In the present study, matrix metalloproteinases (MMPs) were analysed in a mouse model of CM with Plasmodium berghei ANKA. Increased numbers of gelatinase B (MMP-9)positive cells, which were also $\mathrm{CD}_{11 \mathrm{~b}}{ }^{+}$, were detected in the brain. In addition, activation of gelatinase $\mathrm{B}$ occurred in CM brains, and not in brains of mice with non-CM. However, selective genetic knockout of gelatinase B did not alter the clinical evolution of experimental CM. To study other protease balances, the mRNA expression levels of nine matrix metalloproteinases (MMPs), five membrane-type MMPs, TNF- $\alpha$ converting enzyme (TACE) and the four tissue inhibitors of metalloproteinases (TIMPs) were analysed during CM in different organs. Significant alterations in expression were observed, including increases of the mRNAs of MMP-3, $-8,-13$ and -14 in the spleen, MMP-8, $-12,-13$ and -14 in the liver and MMP-8 and -13 in the brain. Net gelatinolytic activity, independent of gelatinase B and inhibitable with EDTA, was detected in situ in the endothelia of blood vessels in $\mathrm{CM}$ brains, but not in brains of mice with non-CM, suggesting that metalloproteases, different from gelatinase B, are active in the BBB environment in CM. The increase in MMP expression in the brain was significantly less pronounced after infection of $\mathrm{C} 57 \mathrm{BI} / 6$ mice with the noncerebral strain $P$. berghei NK65, but it was similar in CM-susceptible C57BI/6 and CM-resistant Balb/C mice upon infection with $P$. berghei ANKA. Furthermore, in comparison with $\mathrm{C} 57 \mathrm{BI} / 6 \mathrm{mice}$, a larger increase in TIMP-1 and a marked, $>30$-fold induction in MMP-3 were found in the brains of Balb/C mice, suggesting possible protective roles for TIMP-1 and MMP-3.
\end{abstract}

Laboratory Investigation (2006) 86, 873-888. doi:10.1038/labinvest.3700454; published online 24 July 2006

Keywords: cerebral malaria; gelatinase; matrix metalloproteinase; Plasmodium berghei ANKA; RT-PCR; zymography

Malaria is caused by protozoa of the genus Plasmodium, of which four species can infect humans. Although the genetics of the parasite ${ }^{1}$ and the vector $^{2}$ have been well studied, insights into crucial mammalian host genes that may be useful targets for therapy are lacking. P. falciparum is the most virulent species in humans, and $P$. vivax, $P$. ovale and $P$. malariae are less a cause of lethality. Worldwide, every year about 300 million acute illnesses

Correspondence: Dr PE Van den Steen, PhD, Laboratory of Immunobiology, Rega Institute for Medical Research, University of Leuven, Minderbroedersstraat 10, Leuven 3000, Belgium.

E-mail: philippe.vandensteen@rega.kuleuven.ac.be

Received 16 May 2006; revised and accepted 14 June 2006; published online 24 July 2006 and more than one million deaths are reported, most of which occur in sub-Saharan Africa (www.who.int).

One of the major causes of lethality is a complication called cerebral malaria (CM). To escape the macrophages in the spleen, the late stages (late trophozoites and schizonts) of the parasite in the erythrocyte express proteins (eg erythrocyte membrane protein-1, PfEMP-1, in P. falciparum) at the surface of the erythrocyte, which mediate attachment of the infected erythrocyte to endothelia, in particular to those in the brain. This phenomenon leads to congestion of the blood vessels and to local inflammation. Subsequent neurological symptoms develop, ending in coma and death. ${ }^{3}$ The exact causes of the neurological problems are not fully 
understood, but it is generally accepted that both metabolic insufficiencies (eg hypoxia, due to the congestion) and immunological reactions play a role $^{4,5}$ A considerable number of leukocytes also marginate and participate in a local immune response. ${ }^{6}$ Platelets also adhere to the activated brain endothelium in CM and play a role in the pathogenesis. $^{7}$ In vitro, P. falciparum-infected erythrocytes induce caspase-activation and apoptosis of human endothelial cells, indicating another possible pathogenic mechanism. ${ }^{8}$ Both in humans and in mice, it was shown that the blood-brain barrier (BBB) is disrupted, which leads to mild to severe brain oedema. ${ }^{9}$ Oedema formation further worsens the hypoxia by compressing cerebral blood vessels, leading to a collapsed blood flow, which is probably the ultimate cause of death in mice. ${ }^{10}$

In a widely used mouse model with the parasite $P$. berghei ANKA, several proinflammatory cytokines and cytokine-receptors play an essential role in the development of CM. ${ }^{6}$ These include, for example, interferon $-\gamma$ (IFN- $\gamma$ ), IFN- $\gamma$ receptor, lymphotoxin- $\alpha$ and tumor necrosis factor receptor-2. ${ }^{11-14}$ Also, TNF$\alpha$ has been associated with CM (for a review, see Hunt and $\mathrm{Grau}^{6}$ and Gimenez et $a l^{15}$ ). Until now, mainly regulatory molecules of the immune system have been investigated, with less attention to effector molecules. One exception is perforin from $\mathrm{CD}^{+}$T-cells, which is also essential for the neurological symptoms in mice. ${ }^{16-18}$

Since the BBB is disrupted during CM, it is tempting to speculate that proteases of the extracellular matrix are involved. One such class of proteases are the matrix metalloproteinases (MMPs). MMPs are neutral $\mathrm{Zn}^{2+}$-dependent endopeptidases with a number of conserved domains, including the pro-, catalytic and $\mathrm{Zn}^{2+}$-binding domains and most have a carboxyterminal hemopexin domain. ${ }^{19,20}$ Some MMPs have additional domains, for example, membrane type (MT)-MMPs have a carboxyterminal membrane anchor, and gelatinases have a gelatinbinding fibronectin-like domain. MMPs have distinct but overlapping substrate specificities and degrade highly efficiently components of the extracellular matrix. It is generally accepted that overproduction of these MMPs leads to tissue destruction and pathology, when not counterbalanced by their physiological inhibitors, the tissue inhibitors of metalloproteinases (TIMPs). One particular MMP, gelatinase B or MMP-9, has been implicated in the degradation of the BBB in various diseases. ${ }^{21-27}$ In addition, malaria-derived hemozoin has recently been shown to induce gelatinase B in a TNF- $\alpha$ dependent manner. ${ }^{28}$ Furthermore, MMPs have been suggested to be involved in the shedding of membrane-bound TNF- $\alpha .{ }^{29,30}$ However, the main activator of pro-TNF- $\alpha$ is a non-MMP metalloproteinase, namely TNF- $\alpha$ converting enzyme (TACE), also called A Disintegrin and Metalloproteinase (ADAM)-17. ${ }^{31,32}$ It was therefore relevant to analyse MMPs, TACE and TIMPs during CM.

\section{Materials and methods}

\section{Infection of Mice with $P$. berghei}

C57Bl/6 J mice or gelatinase B knockout mice, which were backcrossed to a $\mathrm{C} 57 \mathrm{Bl} / 6 \mathrm{~J}$ background for 10 generations, were injected intraperitoneally (i.p.) with $10^{4}$ P. berghei ANKA parasites (a kind gift of Professor Dr A Waters and Professor Dr C Jansse, Leiden University Medical Centre, The Netherlands). For the analysis of non-CM, C57Bl/6 mice were infected with the parasite strain $P$. berghei NK65 (a kind gift of Professor Dr D Walliker, University of Edinburgh, Scotland, UK) ${ }^{33}$ or Balb/C mice were infected with $P$. berghei ANKA. Mice with non-CM displayed no signs of CM, and died 2-3 weeks after infection with elevated $(>30 \%)$ parasitemia. The percentage of infected erythrocytes in the peripheral blood was determined by microscopical analysis after Giemsa-staining. Statistical analyses of Kaplan-Meyer mortality curves were performed with the log-rank test software on the website of the Walter and Eliza Hall Institute (WEHI). All experiments were approved by the local ethical committee (Licence LA121251, Belgium).

\section{Ribonuclease Protection Assays (RPAs) and RT-PCR}

At the indicated time intervals, inoculated mice or the corresponding controls were killed. Heparinised blood was collected by heart puncture and organs were removed and homogenised in TRIzol extraction reagent (Invitrogen, Carlsbad, CA, USA). RNA was extracted according to the procedure of the manufacturer and quantified by UV absorption. RPAs were performed as previously described. ${ }^{34}$ Quantitative RT-PCR on $1 \mu \mathrm{g}$ RNA/sample was performed with the corresponding MMP/TACE primer and probe sets from Applied Biosystems (Foster City, CA, USA) on an ABI Prism 7000 Sequence Detection System apparatus (Applied Biosystems). As a control for the mRNA quantification, ribosomal 18S mRNA was also quantified by RT-PCR and found to remain constant in the different organs during the course of infection.

\section{Zymography}

At the indicated time intervals, inoculated mice or the corresponding controls were killed. Heparinised blood was collected by heart puncture and organs were removed and homogenised in organ lysis buffer (50 mM Tris-HCl pH 7.4, $10 \mathrm{mM} \mathrm{CaCl}_{2}, 5 \mathrm{mM}$ $o$-phenantroline, $2 \mathrm{mM}$ DTE, $0.1 \%$ Triton X-100, protease inhibitor cocktail (Complete, EDTA-free, Roche Diagnostics, Mannheim, Germany)). After centrifugation to remove insoluble debris, gelatinases in the extracts were prepurified by binding to gelatin-Sepharose, as described.$^{35}$ Subsequently, the prepurified gelatinases were analysed by gelatin 
zymography. ${ }^{36}$ The amounts loaded on zymography are the equivalent of $2 \mathrm{mg}$ original tissue for lungs, kidneys, livers and spleens and of $30 \mathrm{mg}$ brain tissue. As a molecular weight standard, we used a mixture of $1 \mathrm{ng}$ recombinant human full-length progelatinase B (92 and $200 \mathrm{kDa}$ ) and $1 \mathrm{ng}$ of two different recombinant gelatinase $\mathrm{B}$ mutants, lacking the hemopexin domain (72 and $144 \mathrm{kDa}$ ) or both the hemopexin and collagen V-like domains (48 kDa), all produced in Sf9 insect cells.

\section{In Situ Zymography}

Gelatin in situ zymography was performed on $5-\mu \mathrm{m}$ thick frozen brain sections, according to a modified protocol. $^{37,38}$ After cutting, the sections were allowed to dry and subsequently incubated for $3 \mathrm{~h}$ at $37^{\circ} \mathrm{C}$ with $20 \mu \mathrm{g} / \mathrm{ml}$ quenched FITC-labelled gelatin (DQ gelatin, Molecular Probes, The Netherlands) in the following buffer: $50 \mathrm{mM}$ Tris-HCl pH 7.5, $150 \mathrm{mM} \mathrm{NaCl}, 5 \mathrm{mM} \mathrm{CaCl}_{2}, 0.2 \mathrm{mM} \mathrm{NaN}_{3}$, to which $20 \mu \mathrm{g} / \mathrm{ml}$ unlabelled gelatin and a protease-inhibitor cocktail (Complete, EDTA-free from Roche) was added. This cocktail contains inhibitors against all classes of proteases except metalloproteases. After incubation, the sections were examined under the fluorescence microscope to localise the sites at which gelatinolysis occurred. As a control, $15 \mathrm{mM}$ EDTA was added to inhibit metalloproteases.

\section{Immunohistochemistry}

Frozen sections of $10 \mu \mathrm{m}$ were fixed in $10 \%$ neutral formalin (Sigma), washed in PBS and blocked with $1 \%$ BSA for $30 \mathrm{~min}$. The sections were incubated with polyclonal goat anti-mouse MMP-9 antiserum (R\&D Systems, Abingdon, UK; $6 \mu \mathrm{g} / \mathrm{ml}$ ) for $2 \mathrm{~h}$, washed and incubated with FITC-labelled donkey anti-goat IgG (Jackson ImmunoResearch, Cambridgeshire, UK). In the case of double staining, phycoerythrin(PE)-labelled anti-CD11b (Beckton-Dickinson, Erembodegem, Belgium) was added together with the FITC-labelled donkey anti-goat IgG. For staining of neutrophils, fixed and blocked sections were incubated with PE-labelled anti-mouse Gr-1 antibody (eBioscience, San Diego, CA, USA). For this staining, sections of a spleen of an uninfected wild-type mouse were used as a position control. After a final wash, the sections were mounted with ProLong Gold Antifade (Invitrogen) and examined under the fluorescence microscope. Bright-green gelatinase $\mathrm{B}^{+}$cells were counted in 20 fields $(20 \times$ magnification) of cerebral cortex or cerebellum.

\section{Treatment with the MMP-Inhibitor BB-94}

Six days after infection, mice were injected i.p. with a single dose of $50 \mathrm{mg} / \mathrm{kg}$ BB-94 (Batimastat, British Biotech, UK), resuspended at $3 \mathrm{mg} / \mathrm{ml}$ in
PBS $+0.01 \%$ Tween-20. Control mice were injected with the corresponding volume of PBS $+0.01 \%$ Tween-20.

\section{Results}

\section{Zymography Analysis of Gelatinases A and B during} Experimental CM

Gelatinase B/MMP-9 has been shown to be crucial for the disruption of the BBB in several diseases and is also an important modulator of immune reactions, in particular by processing cytokines and chemokines. ${ }^{39,24}$ Therefore, it was relevant to compare the expression of gelatinases by gelatin zymography analysis during the course of experimental CM in the brain and in organs important for immune reactions against the parasite, including spleen and liver.

Mice were inoculated with $P$. berghei ANKAinfected red blood cells. Infected erythrocytes (0.5$2 \%$ ) were detected in the peripheral blood after 6 days, and the parasitemia increased and reached 7$10 \%$ infected erythrocytes after 8 days. Most mice ( $\sim 95 \%$ ) died of CM after 8-10 days. Organ extracts at different intervals during the disease were prepared, prepurified on gelatin-Sepharose and analysed by gelatin zymography (Figure 1). Levels of gelatinase A (MMP-2), which is expressed relatively constitutively by many cell types, decreased slightly in the serum (data not shown), kidneys and spleen, and increased slightly in the brain 8 days after infection (Figures 1 and 2). In contrast, a marked increase of progelatinase B was noticed in the liver.

In addition to the highly sensitive detection of different amounts of gelatinases, gelatin zymography is a useful tool to analyse the various molecular forms of gelatinases. In particular, activated forms are easily distinguished from the inactive proforms because activation results in a decrease of the molecular weight. Interestingly, activation of (pro)gelatinase $\mathrm{B}$ was best observed in the brain after 8 days, concomitantly with the occurrence of the cerebral symptoms (Figures 1 and 2). The identities of progelatinase B and of the activated gelatinase B band were confirmed by their absence in gelatinase B knockout mice (see Figure 2). To evaluate whether the activation of gelatinase $\mathrm{B}$ occurs in malarial infections without cerebral complications, C57Bl/6 mice were infected with $P$. berghei NK65, a similar parasite strain that does not cause CM. Also, Balb/C mice, which are resistant to CM, were infected with P. berghei ANKA. In both cases, similar degrees of parasitemia $(7-10 \%)$ as in mice with CM were obtained after 8 days, but the symptoms of CM were completely absent and the mice appeared healthy. Gelatin zymography analysis of brain extracts of these mice indicated that the activation of gelatinase B was significantly less apparent $(P<0.003$ in both cases) than in mice with $\mathrm{CM}$, suggesting that this activation is specific for CM (Figure 2). 



Figure 1 Gelatin-zymography analysis of organ extracts of mice infected with $P$. berghei ANKA. C57Bl/6 mice were infected with $P$. berghei ANKA and killed at the indicated days after infection. Extracts of the organs of three mice at each time point were analysed by gelatin zymography to measure the amounts and the molecular forms of gelatinase A and B (MMP-2 and -9). The gelatinase B monomers $(110 \mathrm{kDa})$ and dimers $(220 \mathrm{kDa})$ are indicated with open arrowheads and activated monomers $(95 \mathrm{kDa})$ with open arrowheads annotated with 'act'. Gelatinase A is indicated with filled arrowheads. The molecular weights of a standard gelatinase preparation are indicated in $\mathrm{kDa}$. Quantification by scanning densitometry of the zymolytic bands of progelatinase B (black bars), activated gelatinase B (hatched bars) and gelatinase A (grey bars) is shown in the graphs at the right, and the statistical differences with the uninfected controls are indicated $\left({ }^{*} P<0.05 ;{ }^{*} P<0.02 ;{ }^{* *} P<0.002\right)$. St, standard gelatinase preparation; Con, organ extracts of uninfected control mice; D2, 2 days after infection.

\section{Gelatinase B in the Brain of Infected Mice is} Associated with CD11b ${ }^{+}$Cells

To localise gelatinase $\mathrm{B}$ in the brain of mice with $\mathrm{CM}$, immunohistochemistry on frozen sections was performed (Figure 3). Bright gelatinase $\mathrm{B}^{+}$cells were detected in wild-type mice and were absent in gelatinase B knockout mice. The numbers of gelatinase $\mathrm{B}^{+}$cells were 10 -fold increased in brains (cerebral cortex and cerebellum) of mice with CM vs uninfected animals. This is apparently in contradiction with the relatively modest increase in gelatinase B as detected by zymography (Figures 1 and 2), but in total brain extracts the local increase 
a

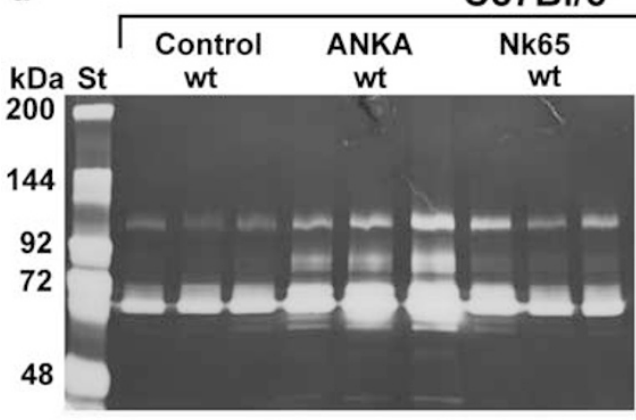

b

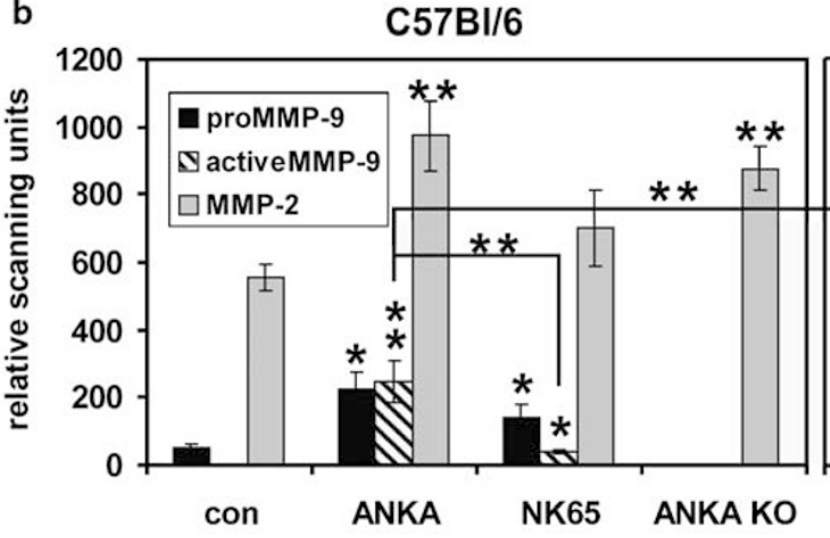

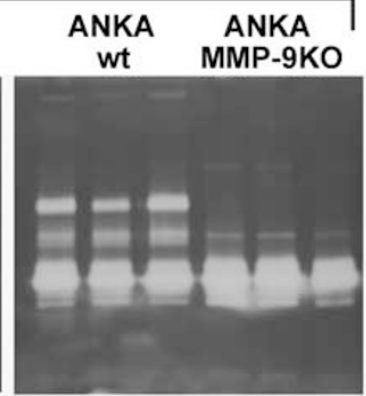

\section{Balb/c}

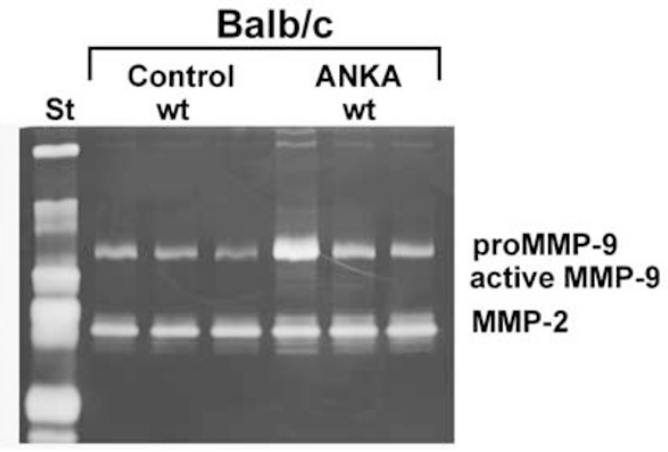

Balb/c

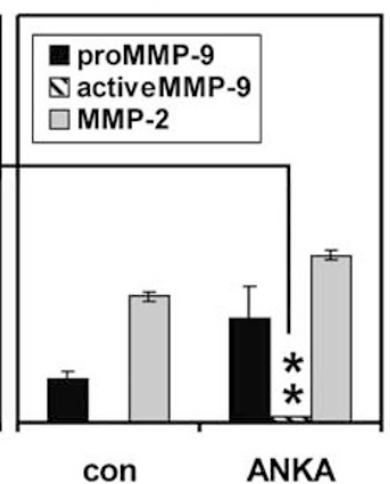

Figure 2 Gelatin-zymography analysis of brain extracts of mice infected with P. berghei ANKA and P. berghei NK65. (a) C57Bl/6 wild type or gelatinase B knockout or Balb/C wild-type mice were infected with $P$. berghei ANKA or with $P$. berghei NK65 and killed after 8 days. Extracts of the brains of these mice were analysed by gelatin zymography and compared with brain extracts of three uninfected control mice (Con) to measure the amounts and the molecular forms of gelatinase A and B (MMP-2 and -9), which are indicated. The faint and sharply delineated zymolytic band around $85 \mathrm{kDa}$ in the brain extracts of the gelatinase B knockout mice is unrelated to gelatinase B. The molecular weights of a standard gelatinase preparation are indicated in $\mathrm{kDa}$. St, standard gelatinase preparation. (b) The zymolytic bands shown in panel a were quantified by scanning densitometry. Significant differences with the uninfected controls and between ANKAand NK65-infected C57Bl/6 mice and ANKA-infected Balb/c mice are indicated $\left({ }^{*} P<0.05 ;{ }^{*} P<0.02\right)$. Histogram colour code is as in Figure 1.

in these scattered gelatinase $\mathrm{B}^{+}$cells might not be detectable. Double immunostaining showed that all these gelatinase B-expressing cells are $\mathrm{CD}_{1}{ }^{+}$, indicating a myeloid origin of these cells.

\section{CM in Gelatinase B Knockout Mice}

The destruction of the BBB and the associated brain pathology may be a cause of mortality during CM. Since we observed expression and activation of gelatinase $B$ in the brain and since gelatinase $B$ is involved in the destruction of the $\mathrm{BBB}$, we compared the mortality caused by CM in gelatinase $B$ knockout and corresponding wild-type mice. As indicated in Figure 4a, no difference in lethality was observed in the gelatinase B knockout mice $v s$ wildtype mice. As an internal control of infection, no significant differences in parasitemia were observed between the two animal populations during the course of disease (data not shown). Since some induced phenotypes in gelatinase B knockout mice are different in young mice compared to adult mice, ${ }^{40,41}$ we performed a similar analysis in young gelatinase B knockout and corresponding wild type mice of 3 weeks. No significant differences of mortality and parasitemia were observed (Figure 4b). As a conclusion, gelatinase B does not play an indispensable role in the pathogenesis of CM.

\section{Expression of MMPs during the Course of Experimental CM}

MMP-9 acts together with other MMPs in disease processes in a so-called MMP cascade. ${ }^{25}$ In order to study the expression and involvement of other MMPs during the disease development, the mRNAs of a large number of MMPs and MT-MMPs were analysed by RPA at different time intervals and in various organs. After 6-8 days, the mRNAs of several MMPs were increased in liver, spleen and lungs (Figure 5). In particular, marked increases of MMP-8, -12 and -13 in the liver, of MMP-3, -8, -9, and -13 in the spleen and MMP-8 and -9 in the lungs were noticed. Also, a decrease of MMP-11 in kidneys and lungs was observed at 6 and 8 days of disease development. In the brain, the mRNAs of 

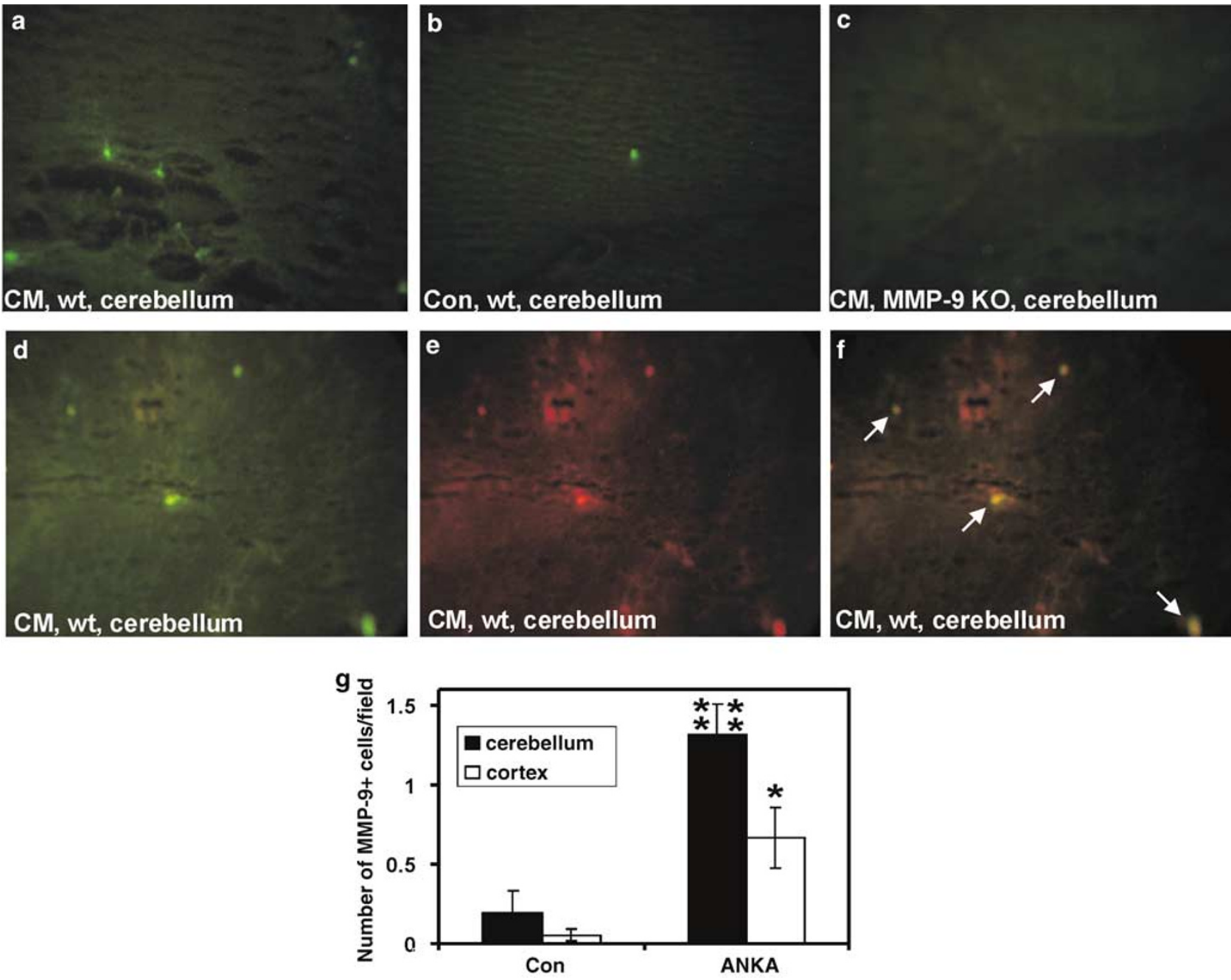

Figure 3 Immunohistochemical localisation of gelatinase B in the brain of mice with CM. Frozen sections of mice with CM (a, c-f) or uninfected mice (b) were stained with an antiserum specific for gelatinase B (green). Sections of gelatinase B knockout mice (c) were used as negative controls. To further characterise the gelatinase $\mathrm{B}^{+}$cells, double immunostaining with CD11b (red) was performed. In (d), the green fluorescence of gelatinase $\mathrm{B}^{+}$cells in a double-stained section are shown, and in (e) the red fluorescence of CD11b $\mathrm{b}^{+}$cells is obvious in the same field. In (f), panels $\mathbf{d}$ and $\mathbf{e}$ were merged and colocalisation is indicated by the white arrows. (g) The number of gelatinase $\mathrm{B}^{+}$cells were counted in 20 fields of cerebral cortex or cerebellum and compared between uninfected mice and mice with CM. ${ }^{*} P<0.05 ; * * * * P<2 \times 10^{-6}$.

most MMPs were below the detection limit of the RPA. Therefore, RT-PCR for MMP-2, $-3,-7,-8,-9,-11$, -12 and -13 was performed on the brain mRNA samples (Figure 6). Marked increases of MMP-8 and MMP-13 at day 6 and day 8 were detected, and also an increase of MMP-3 at day 8. In accordance with the zymography data in Figures 1 and 2, gelatinase B/MMP-9 mRNA was only modestly increased. MMP-12 mRNA was significantly decreased at day 8, and MMP-11 remained unchanged during the disease course. MMP-2 and MMP-7 mRNAs remained below the detection limits. Since MMP-8, which is a main MMP from neutrophils, was strongly increased in the brain, it was analysed by immunohistochemistry for the neutrophil marker Gr-1 whether neutrophils were trapped in the vessels. No immunoreactivity with anti-Gr-1 was found, indicating that MMP-8 is presumably pro- duced by other cells than neutrophils (data not shown).

For the MT-MMPs, an increase of MT1-MMP (MMP-14) mRNA in liver, spleen and kidneys was detected, and MT2-MMP (MMP-15) decreased in the liver and kidneys while the disease progressed (Figure 5). In the brain, MT-MMPs were detected and remained unchanged (data not shown). These alterations in expression of MMPs during the course of $\mathrm{CM}$ are summarised as a part of Table 1.

\section{Expression of TACE/ADAM-17 during the Course of Experimental CM}

TACE, also named A Disintegrin And Metalloproteinase (ADAM)-17, is the most important sheddase of membrane-bound TNF- $\alpha^{31,32}$ Therefore, the 

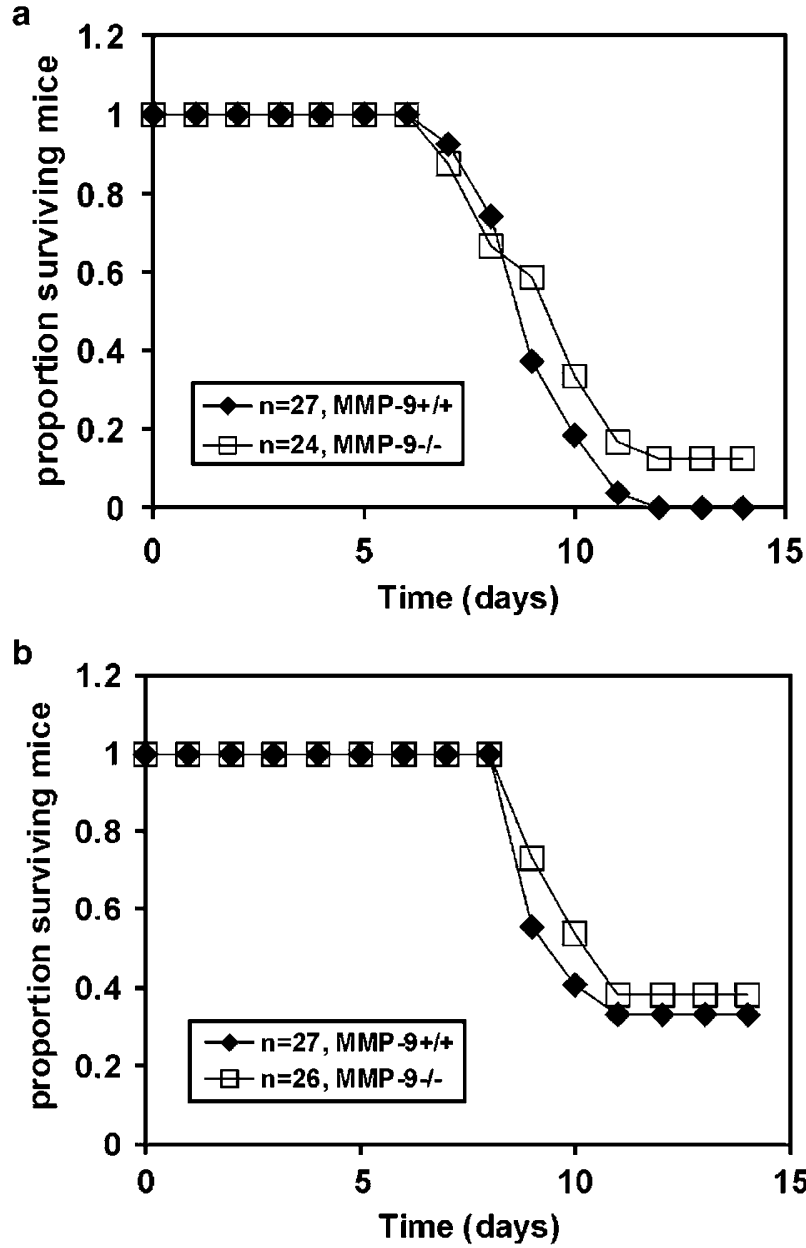

Figure 4 Disease course of CM in adult and young gelatinase B knockout and wild-type mice. (a) Adult (8-10 weeks old) gelatinase B knockout ( $\square, n=24$ ) and corresponding wild-type $(\diamond, n=27)$ mice were infected with $P$. berghei ANKA. The mortality of both groups was followed after infection. The difference between the gelatinase B knockout and wild-type mice was not significant. (b) The mortality of young (3 weeks old) gelatinase B knock-out $(\square, n=26)$ and corresponding wild-type $(\diamond, n=27)$ mice was followed after infection with $P$. berghei ANKA. The difference between the gelatinase B knockout and wild-type mice was not significant.

expression of TACE was analysed by RT-PCR in the mRNA samples of the different organs during the course of experimental CM (Figure 7). TACE mRNA was significantly increased at day 6 in liver and spleen, and returned to basal levels at day 8 .

\section{Expression of TIMPs in the Course of Experimental CM}

An important regulation mechanism for the activity of MMPs and MT-MMPs in the extracellular space is inhibition by TIMPs. In fact, the biological activity of any MMP is regulated by the balance between the activated MMP and the different TIMPs. ${ }^{42}$ Also, TACE is regulated by inhibition by TIMP-3 (but not by TIMP-1, -2 or -4$).{ }^{43}$ Therefore, the mRNAs for TIMPs were also analysed by RPA. A marked increase of TIMP-3 and TIMP-1 was observed in liver and spleen at days 6 and 8 after infection (Figure 8a and b), while no changes in the expression of TIMPs were detected in lungs and kidneys (summarised in Table 1). Since TIMP-1 remained below the detection limit of the RPA in the brain, RT-PCR was performed, and a four-fold increase in TIMP-1 mRNA expression was documented (Figure 8c).

\section{Localisation of Net Proteolytic Activity in Brains from Mice with CM by In Situ Zymography}

The observations of increased expression of MMPs and the activated forms of MMP-9, concomitant with a limited increase in the expression of TIMP-1, raises the question whether uninhibited, 'net' proteolytic activity might be present in brains from mice with CM. To test this hypothesis, proteolytic activity was measured in situ in brain sections using quenched FITC-labelled gelatin (Figure 9). In brains from uninfected control mice, only a low level of activity was associated with the meninges and septum and its large blood vessels, and also with cell bodies throughout the brain. In the brains from mice with CM, bright fluorescence was detected, indicating strong net gelatinolytic activity. This activity was mainly associated with blood vessels, including both small capillaries and larger blood vessels, and was particularly obvious in the granular layer and white matter in the cerebellum. In the cortex, a large number of capillaries contained gelatinolytic activity and also some larger vessels in the septum showed bright fluorescence. Similar patterns were observed in gelatinase B knockout mice and were unaffected by a general protease inhibitor against all classes of proteases except metalloproteases. However, the activity was completely disrupted in the presence of EDTA. Furthermore, little gelatinolytic activity was observed in the brains of infected Balb/C mice, which are resistant to CM. This shows for the first time that intense, metalloprotease-dependent proteolytic activity in small and large blood vessels is associated with CM.

\section{Inhibition of MMPs with BB-94 Delays Experimental CM}

To determine whether MMPs and/or TACE play a role in experimental CM, infected mice were injected with the broad-spectrum MMP- and TACE-inhibitor BB-94. We choose to inject the inhibitor i.p. at day 6 during the course of infection, when the expression of MMPs and TACE starts to increase. At the used dosage, sufficient levels of the inhibitor remain present in the organism to inhibit most MMPs during at least 3 days. ${ }^{44}$ By this treatment, the mice died only 1 day later, but this 

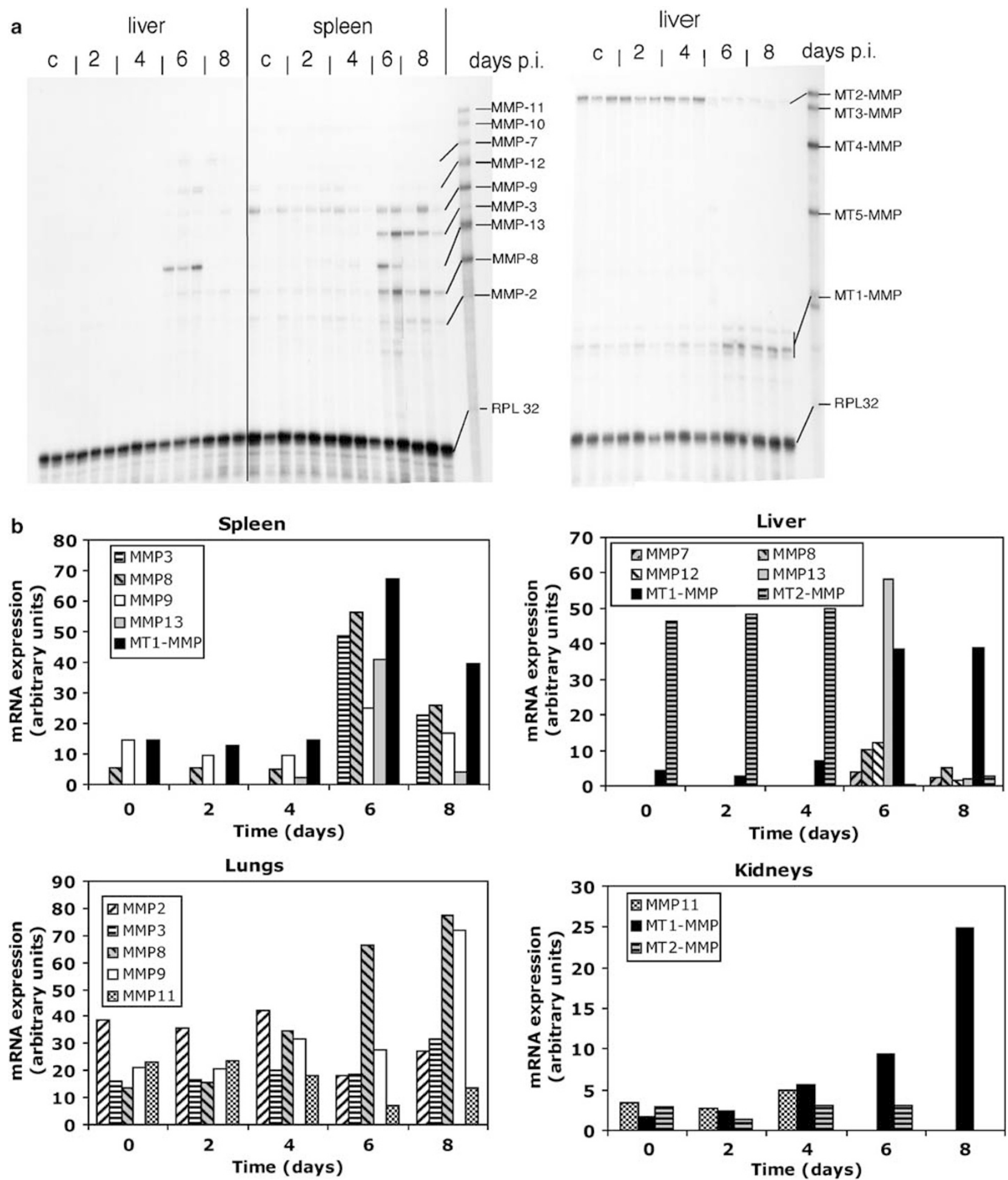

Figure 5 Detection of organ-specific mRNA expression of MMPs and MT-MMPs during the development of CM in mice. C57Bl/6 mice were infected with $P$. berghei ANKA and spleen, lungs, kidneys and liver were dissected at the indicated times (three mice for each time point) and used for mRNA preparation. After electrophoresis, the mRNAs of different MMPs and MT-MMPs were detected using radiolabelled probes. The house-keeping gene RPL32 was used as a reference control. (a) A limited set of autoradiographs of some organs are shown as examples. (b) Autoradiographs for the expression of MMPs and MT-MMPs were scanned, quantified by densitometry ( $n=3$ for each time point) and normalised with the RPL32 mRNA as reference. A selected set of averaged data, containing all observed alterations as a function of time, are shown. C, uninfected control; p.i., postinfection. 


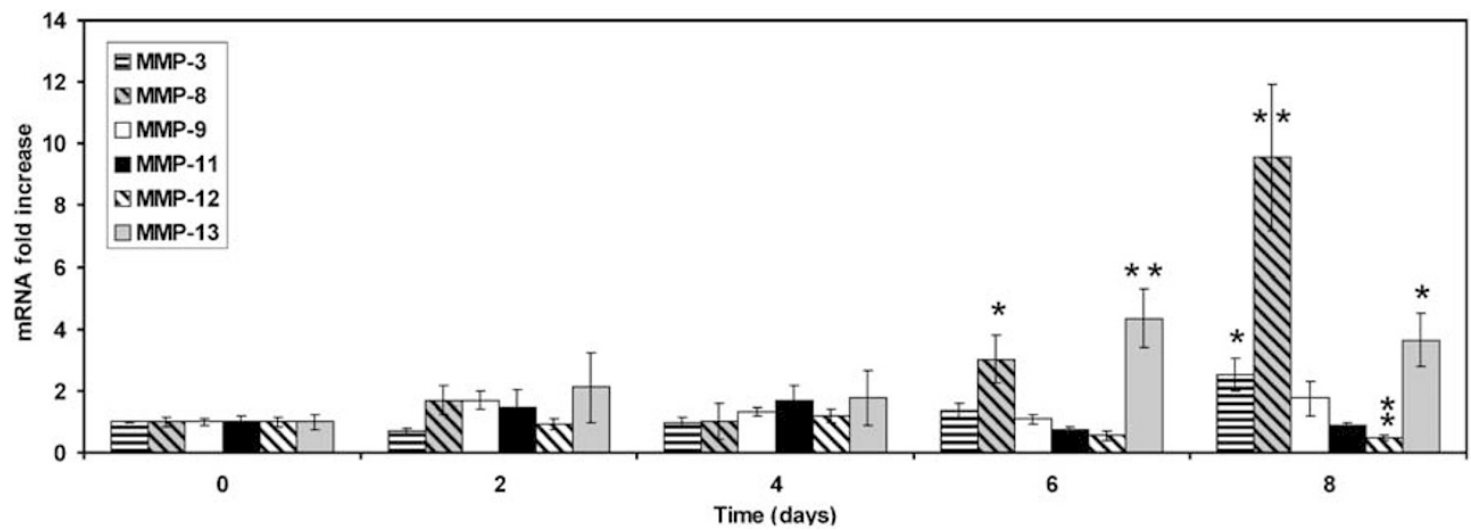

Figure 6 Detection of the mRNA of MMPs by RT-PCR in the brain during development of CM in mice. Brains from C57Bl/6 mice (three mice per indicated time point) infected with P. berghei ANKA were dissected and homogenised at the indicated time points during the course of the disease. mRNA was isolated, quantified and subjected to RT-PCR for soluble MMPs. Relative mRNA levels are indicated as fold increases compared to mRNA from uninfected mice. MMP-2 and -7 remained below the detection limit. 18S mRNA was used as a control for the quantification of total mRNA. ${ }^{*} P<0.05 ;{ }^{*} P<0.02$.

Table 1 Changes in expression of MMPs, TACE and TIMPs during CM

\begin{tabular}{l|l|l|l|l|l}
\hline & Brain & Liver & Spleen & Lung & Kidney \\
\hline MMP-2 & $\uparrow \mathrm{d} 8^{\mathrm{a}}$ & $-^{\mathrm{a}}$ & $\downarrow d 2-8^{\mathrm{a}}$ & - & $\downarrow d \mathrm{~d} 68^{\mathrm{a}}$ \\
\hline MMP-3 & $\uparrow \mathrm{d} 8$ & $\mathrm{ND}$ & $\uparrow \mathrm{d} 6,8$ & - & $\mathrm{ND}$ \\
\hline MMP-7 & $\mathrm{ND}$ & $\uparrow \mathrm{d} 6,8$ & $\mathrm{ND}$ & $\mathrm{ND}$ & $\mathrm{ND}$ \\
\hline MMP-8 & $\uparrow \mathrm{d} 6,8$ & $\uparrow \mathrm{d} 6,8$ & $\uparrow \mathrm{d} 6,8$ & $\uparrow \mathrm{d} 6,8$ & $\mathrm{ND}$ \\
\hline MMP-9 & $\uparrow \mathrm{d} d 8^{\mathrm{a}}$ & $\uparrow \mathrm{d} 6,8$ & - & $\uparrow \mathrm{rd} 8$ & $\uparrow \mathrm{d} 8$ \\
\hline MMP-11 & - & $\mathrm{ND}$ & $\mathrm{ND}$ & $\downarrow \mathrm{d} 6,8$ & $\downarrow \mathrm{d} 6,8$ \\
\hline MMP-12 & $\downarrow \mathrm{d} 8$ & $\uparrow \mathrm{d} 6$ & $\mathrm{ND}$ & $\mathrm{ND}$ & $\mathrm{ND}$ \\
\hline MMP-13 & $\uparrow \mathrm{d} 6,8$ & $\uparrow \mathrm{d} 6$ & $\uparrow \mathrm{d} 6$ & $\mathrm{ND}$ & $\mathrm{ND}$ \\
\hline MT1 & - & $\uparrow \mathrm{d} 6,8$ & $\uparrow \mathrm{d} 6,8$ & - & $\uparrow \mathrm{d} 6,8$ \\
\hline MT2 & - & $\downarrow d 6,8$ & $\mathrm{ND}$ & - & $\downarrow d \mathrm{~d} 8$ \\
\hline MT3 & - & $\mathrm{ND}$ & $\mathrm{ND}$ & $\mathrm{ND}$ & $\mathrm{ND}$ \\
\hline MT4 & - & $\mathrm{ND}$ & $\mathrm{ND}$ & $\mathrm{ND}$ & $\mathrm{ND}$ \\
\hline MT5 & - & $\mathrm{ND}$ & $\mathrm{ND}$ & $\mathrm{ND}$ & $\mathrm{ND}$ \\
\hline TACE & - & $\uparrow \mathrm{d} 6$ & $\uparrow \mathrm{d} 6$ & - & - \\
\hline TIMP-1 & $\uparrow \mathrm{d} 6,8$ & $\uparrow \mathrm{d} 6,8$ & $\uparrow \mathrm{d} 6,8$ & - & - \\
\hline TIMP-2 & - & $\mathrm{ND}$ & - & - & $\mathrm{ND}$ \\
\hline TIMP-3 & - & $\uparrow \mathrm{d} 6,8$ & $\uparrow \mathrm{d} 6,8$ & - & - \\
\hline TIMP-4 & - & $\mathrm{ND}$ & $\mathrm{ND}$ & $\mathrm{ND}$ & $\mathrm{ND}$ \\
\hline
\end{tabular}

aDetected only by zymography. ND, not detected; -, no change in expression levels compared to uninfected control; $\uparrow$, increase in expression; $\downarrow$, decrease in expression; $\mathrm{A}$, activation of the proenzyme; MTn, MTn-MMP; d, days after infection

delay in mortality was statistically significant by Kaplan-Meier analysis $(P=0.009)$ (Figure 10). Since no differences in parasitemia were observed between controls and BB-94 treated animals, indicating that BB-94 has no effect on parasite growth (data not shown), these data are in line with the idea that

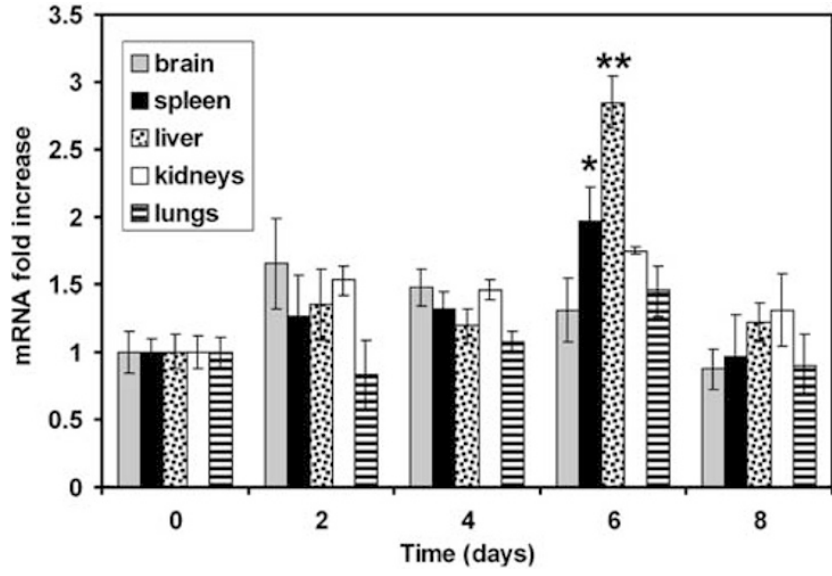

Figure 7 Detection of the mRNA of TACE by RT-PCR in different organs at different times during CM development. Samples of mRNA from the indicated organs of $P$. berghei ANKA-infected mice ( 3 mice per indicated time point) were isolated, quantified and analysed by RT-PCR with a primer and probe set specific for TACE. 18S was used as a control for the quantification of the total mRNA. ${ }^{*} P<0.02 ;{ }^{*} P<0.001$.

the balance between MMPs and inhibitors may influence the course of CM.

\section{Comparison of the Expression of MMPs, TACE and TIMPs in Cerebral vs Non-CM}

While it is tempting to speculate that the increased expression of several MMPs plays a role in the pathogenesis of CM, inhibition of MMPs with the broad-spectrum MMP-inhibitor BB-94 resulted in a delay of CM of only 1 day. The limited effect of this inhibitor might perhaps be explained by the possibility that some MMPs may be disease-promoting, while others could be protective. Therefore, we compared the expression of MMPs, TACE and TIMPs in the brain between CM and non-CM (Figure 11). 
In the brains of $\mathrm{C} 57 \mathrm{Bl} / 6$ mice infected with $P$. berghei NK65, which does not cause CM, the increases in expression of MMP-8 and -13 were significantly attenuated $(P=0.02$ for MMP-8, $P=0.04$ for MMP-13) when compared to mice with CM (infected with $P$. berghei ANKA). In contrast, after infection of CM-resistant Balb/C mice with $P$. berghei ANKA, the expression of MMP-3 was 30fold enhanced, compared to 2.5-fold in mice with CM $(P=0.017$ for the difference in increase), and MMP-8 and -13 were similarly increased as in mice with CM. Furthermore, the increase in expression of TIMP-1 was higher in the Balb/C mice compared to the $\mathrm{C} 57 \mathrm{Bl} / 6$ mice with $\mathrm{CM}$.

\section{Discussion}

In the present study, we first analysed the expression of gelatinase $\mathrm{B}$ in an experimental in vivo model for CM. Zymography analyses of total extracts of different organs were performed, and this revealed a marked increase of gelatinase B in the liver. In the brain of mice with CM, increased numbers of gelatinase $\mathrm{B}^{+}$cells, which were also $\mathrm{CD} 11 \mathrm{~b}^{+}$, were found. In addition, activated forms of gelatinase $\mathrm{B}$ were detected, which are rather specific for CM, since these are significantly less apparent in nonCM (in C57Bl/6 mice infected with $P$. berghei NK65 or Balb/C mice infected with $P$. berghei ANKA). Activated forms of gelatinase B are usually difficult to observe, because they are highly unstable and subject to rapid turnover. The detection of these forms probably reflects that a continuous activation reaction is occurring. This observation is interesting, as gelatinase $\mathrm{B}$ has been implicated in several diseases of the central nervous system. However, no difference in mortality and parasitemia in gelatinase B knockout mice vs wild-type animals was observed, indicating that gelatinase $\mathrm{B}$ is not essential in the pathogenesis of CM. This is in contrast with the essential role of gelatinase $\mathrm{B}$ in other pathological conditions with BBB breakdown, such as, for example, ischemia and multiple sclerosis. ${ }^{21-27,40}$ Therefore, the role of gelatinase B during CM is not yet clear. Several MMPs may act in concert, and elimination of one particular MMP may not necessarily result in a significant effect.

Figure 8 Alterations of the expression of TIMPs during the development of CM. After collection of organs of mice infected with P. berghei ANKA (three mice for each indicated time point), mRNA was isolated and used to document the expression of TIMP-1, $-2,-3$ and -4 and $\alpha 2$-macroglobulin by RPA and/or RTPCR. (a) A limited set of autoradiographs of the RPA of some organs are shown. (b) Autoradiographs for the expression of TIMPs were scanned, quantified by densitometry and normalised with the RPL32 mRNA as reference. A selected set of averaged data, containing all observed alterations as a function of time, are shown. (c) RT-PCR analysis of the expression of TIMPs in the brain. 18S was used as a control for the mRNA concentration. C, uninfected control; p.i., post-infection; $\alpha 2 \mathrm{M}, \alpha_{2}$-macroglobulin.
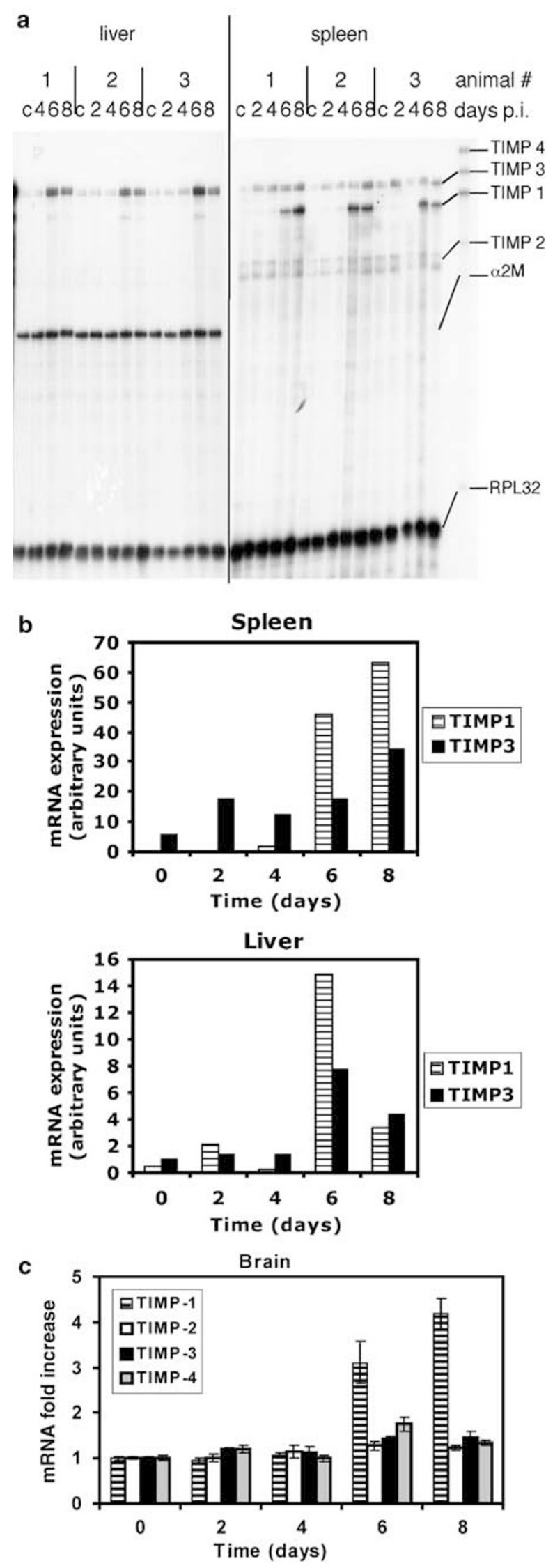

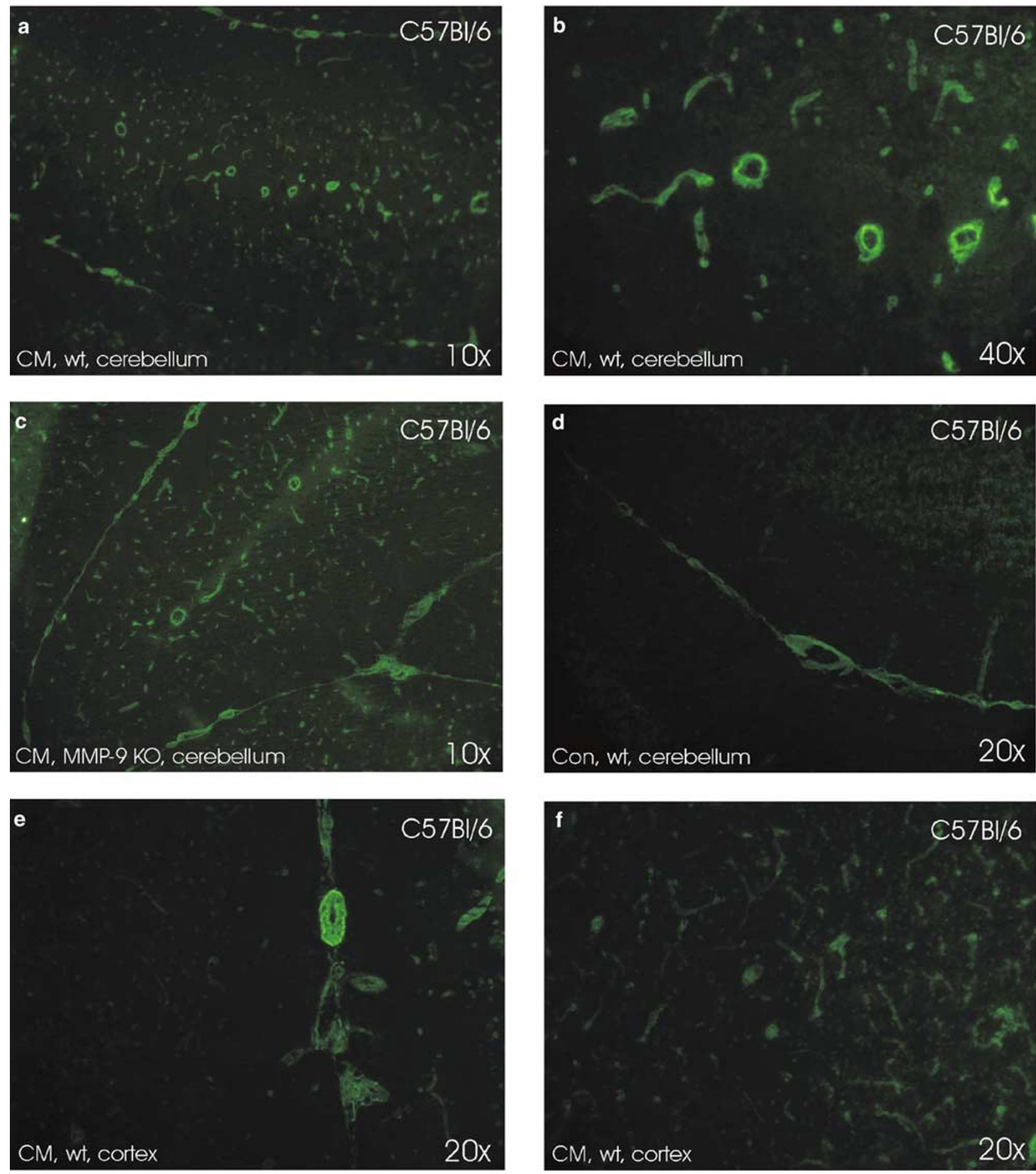

Figure 9 Localisation of gelatinolytic activity in the brain by in situ zymography. Frozen sections of C57Bl/6 mice with CM (8 days after infection) and of different control mice were incubated with quenched FITC-labelled gelatin. Local gelatinolytic activity resulted in dequenching and was visualised by fluorescence microscopy. (a) Cerebellum of wild-type mouse with CM; (b) higher magnification of panel a showing strongly staining blood vessels. (c) Cerebellum from a gelatinase B knockout mouse with CM. (d) Cerebellum from an uninfected control mouse. (e and f) Cortex (with a strongly staining blood vessel in the septum in e) from a wild-type mouse with CM; (g) Cortex from an uninfected control mouse. (h) In the presence of EDTA, no gelatinolytic activity was observed (the cerebellum from a wild-type mouse with CM is shown). (i) Cerebellum of uninfected Balb/C mouse and (j) cerebellum from a CM-resistant Balb/C mouse 8 days after infection with $P$. berghei ANKA. 

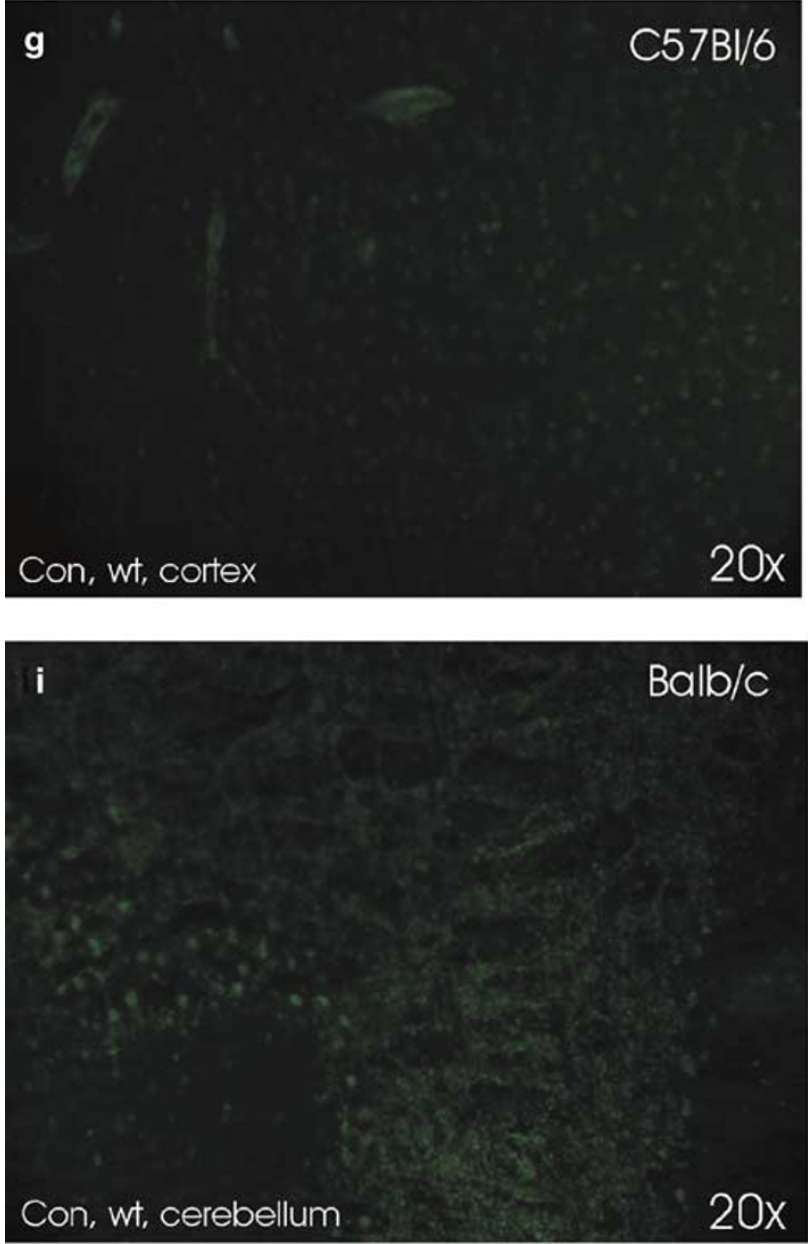

Figure 9 Continued.

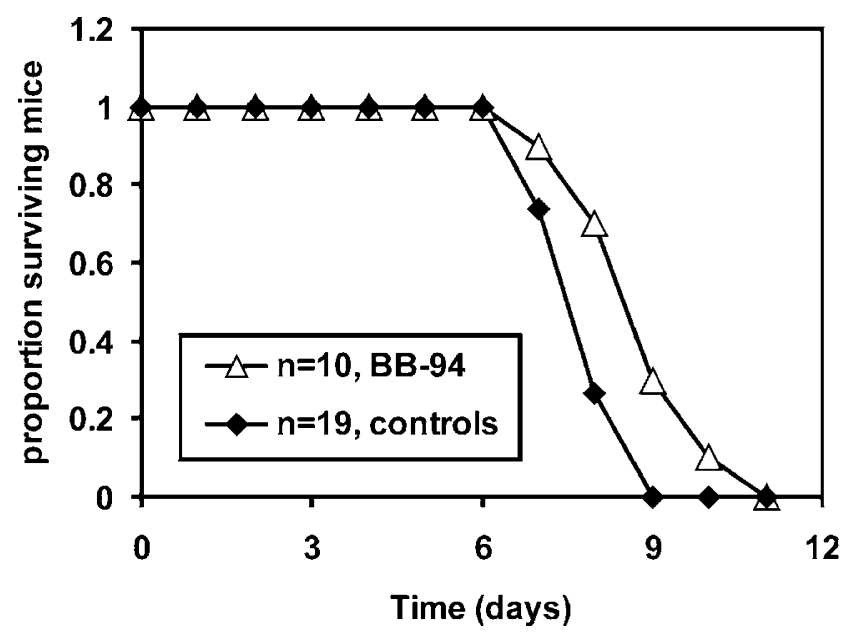

Figure 10 Disease course of CM in mice treated with BB-94. Adult (8 weeks old) C57Bl/6 mice were infected with P. berghei ANKA and treated with BB-94 $(\triangle, n=10)$ or with control solution ( $\bullet$, $n=19) 6$ days after infection. The mortality was followed during the course of the disease and the difference between BB-94 treated and control-treated mice was found to be significant $(P=0.009$, log-rank test). The data are a compilation of two independent experiments, each with a similar and significant $(P<0.05)$ outcome.
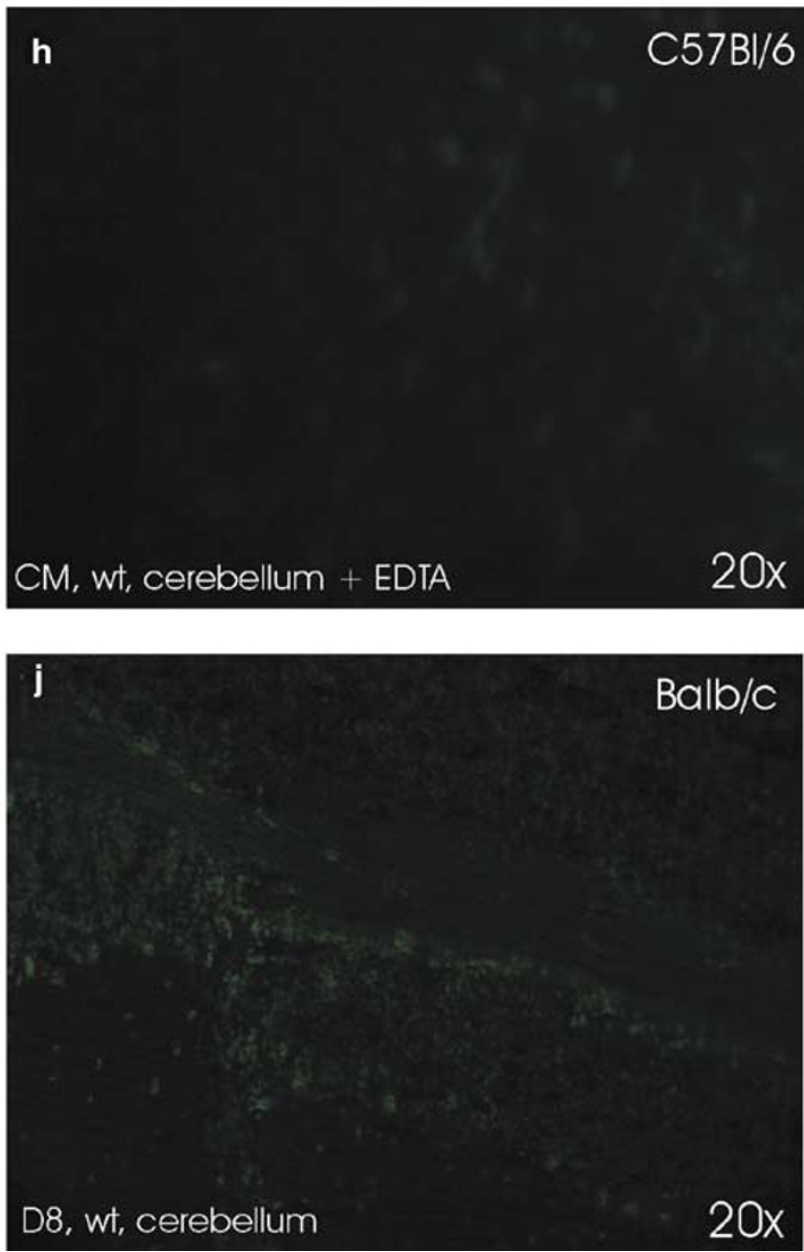

Furthermore, compensatory mechanisms in MMP knockout mice cannot be excluded. ${ }^{45,46}$

As a follow-up, we show in the second part of our study that experimental CM in mice is associated with an increase in the expression of various MMPs and TACE in different organs (summarised in Table 1). The most considerable increases were noticed for the collagenases MMP-8 (neutrophil collagenase) and MMP-13 (collagenase 3) in several organs, including brain. These inductions were pronounced mainly at the end of the disease course when the cerebral symptoms appear. Interestingly, interstitial collagenase (MMP-1) is upregulated in human postmortem brain samples from patients who died from $\mathrm{CM}^{47}$ Also, MMP-3 increased during mouse CM, particularly in the spleen. TACE was increased in spleen and liver before the cerebral symptoms occurred. TACE is considered as the most important sheddase of TNF- $\alpha,{ }^{31,32}$ a cytokine involved in CM, but several MMPs are also able to shed TNF- $\alpha .{ }^{29,30}$ Furthermore, concomitant increases in the expression of the endogenous MMP-inhibitors TIMP-1 and -3 were observed. The exact role of the different MMPs and TIMPs in organs such as spleen, lungs, 

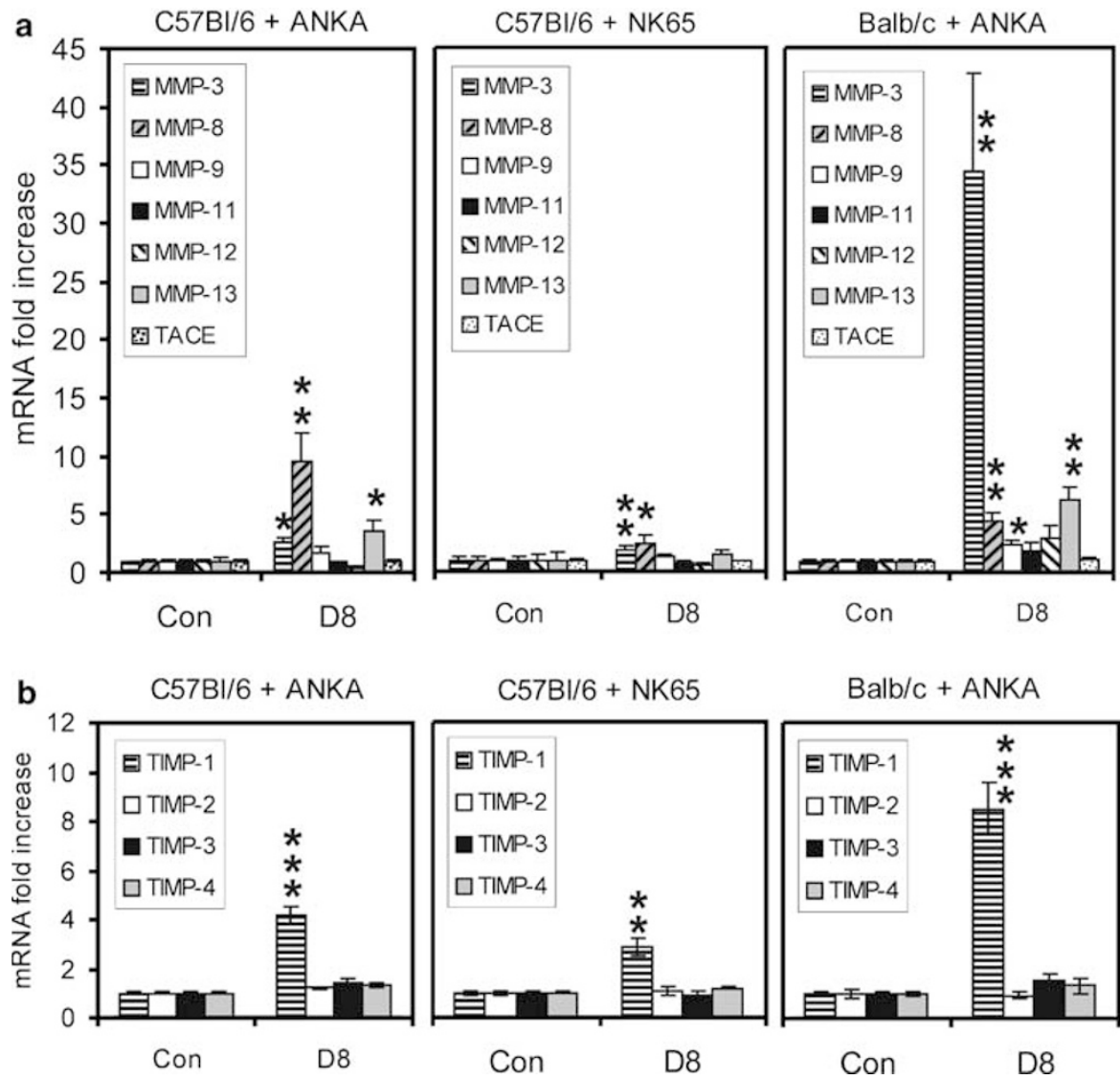

Figure 11 Comparison of the expression of MMPs, TACE and TIMPs in CM and non-CM. C57Bl/6 mice were infected with $P$. berghei ANKA (resulting in CM) or with P. berghei NK65 (non-CM), and Balb/C mice were infected with P. berghei ANKA (non-CM). RNA was extracted from the brains ( $n=3$ for each condition) and RT-PCR was performed to analyse the expression of MMPs and TACE (a) and of TIMPs (b). 18S mRNA was used as a control for the quantification of total mRNA. ${ }^{*} P<0.05 ;{ }^{*} P<0.02 ;{ }^{* *} P<0.001$. Con, uninfected control; D8, 8 days after infection.

liver and kidney in malaria infection is not yet clear. MMPs contribute to organ damage in, for example, the liver or the lungs in other disease models, ${ }^{48-50}$ but also contribute to antimicrobial responses. ${ }^{51,52}$

In the third part of this study, the significance of the expression of MMPs in brain was further examined. Using in situ zymography, intense, 'net' gelatinolytic activity was found to be associated with small capillaries and larger blood vessels in the brains of mice with CM. This activity was EDTAinhibitable and was not found in mice with non-CM. However, it was not abrogated in gelatinase B knockout mice. Therefore, it is likely that this activity is the result of the combined action of several (other) metalloproteases. It is certainly also an indication for the activation of brain endothelial cells, in accordance with the increased expression of intercellular adhesion molecule- $1 .{ }^{53}$

In view of the localisation of metalloproteasedependent gelatinolytic activity at the brain endothelium and since MMPs are capable of degrading several components of the extracellular matrix, it was tempting to speculate that MMPs would participate in the pathogenesis of CM. Inhibition of
MMPs and TACE with the broad-spectrum MMP inhibitor BB-94 resulted in a significant but limited delay of mortality by only 1 day. A possible explanation is that MMPs might fulfil dual roles: while some MMPs may play a disease-promoting role during experimental CM, other MMPs possibly have protective roles, as was also found in other cerebral pathologies. ${ }^{23} \mathrm{~A}$ further complication is that a particular MMP may have different roles in different organs. It is, for example, conceivable that an MMP participates in the degradation of the BBB and at the same time may participate in the immune response in the spleen or liver. Protective roles have also been observed in other diseases: several MMPs are important in wound healing, ${ }^{54}$ remyelination in the brain ${ }^{55}$ and in antimicrobial defence. ${ }^{51,52}$

In this context, the analysis of the expression of MMPs in the brains of mice with non-CM yielded interesting results. In comparison with the brains of mice with CM, the MMP expression was significantly less increased in brains of mice infected with the malaria parasite P. berghei NK65, consistent with the absence of cerebral pathology. However, in brains of CM-resistant Balb/C infected with 
P. berghei ANKA, similar increases in MMP expression were noted as in the susceptible $\mathrm{C} 57 \mathrm{Bl} / 6$ mice with CM, and additionally, a more than 30-fold increase in the expression of MMP-3 (to be compared with a 2.5-fold increase in the CM-susceptible mice) was found. Furthermore, the expression of TIMP-1 was also more increased in the brains of Balb/C mice compared to the $\mathrm{C} 57 \mathrm{Bl} / 6$ mice. This could possibly be consistent with protective functions of both TIMP-1 and MMP-3 in the brain.

All together, the present data open new perspectives in the research on the immunopathological mechanisms in malaria infections. MMPs play important immunoregulatory roles. MMPs influence apoptosis by cleaving Fas-ligand into a soluble form, ${ }^{56}$ and apoptosis of brain endothelial cells was shown to have a role in $\mathrm{CM} .{ }^{8}$ Particularly interesting, MMPs modulate immune responses by cleaving a variety of cytokines, cytokine receptors and chemokines, leading to either activation or inactivation of the cytokine. ${ }^{57-60}$ This includes the activation of membrane-bound TNF- $\alpha$ into its soluble form. ${ }^{29}$ Another metalloprotease important for the shedding of TNF- $\alpha$ is TACE or ADAM17, which is shown here to be increased in liver and spleen of infected mice.

Since specific inhibitors against most of the individual MMPs are lacking, it will be necessary to analyse the disease in the different MMP knockout mice to determine the exact role (protective or detrimental) of each MMP during malaria infections. In addition, malaria parasites synthesise also metalloproteases, which are important, for example, in hemoglobin degradation. ${ }^{61}$ Therefore, the use of particular MMP inhibitors may not only influence host but also parasite pathways. A detailed analysis of the role of each protease together with the development of specific inhibitors might yield novel insights and will indicate whether specific MMPinhibition might be considered for novel therapies.

\section{Acknowledgements}

The kind gifts of Plasmodium berghei ANKA by Professor Dr A Waters and Professor Dr C Jansse (Leiden University Medical Centre, The Netherlands) and of P. berghei NK65 by Professor Dr D Walliker (University of Edinburgh, Scotland, UK) are greatly appreciated. The help of Dr D Daelemans and Dr P Leyssen (Rega Institute, University of Leuven) with the fluorescence microscopy and the RT-PCR is also greatly appreciated. We thank Professor Dr J Van Damme for critical reading of the manuscript and Pepijn De Snijder for his help. PVDS is a postdoctoral fellow of the National Fund for Scientific Research (FWO-Vlaanderen). This study was supported by the FWO-Vlaanderen and the Geconcerteerde OnderzoeksActies 2002-2006 and 2006-2010 and the Rega Centre of Excellence $\mathrm{EF} / 05 / 015$.

\section{Conflicts of interest}

The authors declare to have no conflicts of interest.

\section{References}

1 Gardner MJ, Hall N, Fung E, et al. Genome sequence of the human malaria parasite Plasmodium falciparum. Nature 2002;419:498-511.

2 Holt RA, Subramanian GM, Halpern A, et al. The genome sequence of the malaria mosquito Anopheles gambiae. Science 2002;298:129-149.

3 de Souza JB, Riley EM. Cerebral malaria: the contribution of studies in animal models to our understanding of immunopathogenesis. Microbes Infect 2002;4: 291-300.

4 Sexton AC, Good RT, Hansen DS, et al. Transcriptional profiling reveals suppressed erythropoiesis, up-regulated glycolysis, and interferon-associated responses in murine malaria. J Infect Dis 2004;189:1245-1256.

5 Schofield L, Grau GE. Immunological processes in malaria pathogenesis. Nat Rev Immunol 2005;5: 722-735.

6 Hunt NH, Grau GE. Cytokines: accelerators and brakes in the pathogenesis of cerebral malaria. Trends Immunol 2003;24:491-499.

7 Wassmer SC, Lepolard C, Traore B, et al. Platelets reorient Plasmodium falciparum-infected erythrocyte cytoadhesion to activated endothelial cells. J Infect Dis 2004;189:180-189.

8 Pino P, Vouldoukis I, Kolb JP, et al. Plasmodium falciparum-infected erythrocyte adhesion induces caspase activation and apoptosis in human endothelial cells. J Infect Dis 2003;187:1283-1290.

9 Adams S, Brown H, Turner G. Breaking down the blood-brain barrier: signaling a path to cerebral malaria? Trends Parasitol 2002;18:360-366.

10 Penet MF, Viola A, Confort-Gouny S, et al. Imaging experimental cerebral malaria in vivo: significant role of ischemic brain edema. J Neurosci 2005;25: 7352-7358.

11 Amani V, Vigario AM, Belnoue E, et al. Involvement of IFN-gamma receptor-medicated signaling in pathology and anti-malarial immunity induced by Plasmodium berghei infection. Eur J Immunol 2000;30:1646-1655.

12 Grau GE, Heremans H, Piguet PF, et al. Monoclonal antibody against interferon gamma can prevent experimental cerebral malaria and its associated overproduction of tumor necrosis factor. Proc Natl Acad Sci USA 1989;86:5572-5574.

13 Engwerda CR, Mynott TL, Sawhney S, et al. Locally up-regulated lymphotoxin alpha, not systemic tumor necrosis factor alpha, is the principle mediator of murine cerebral malaria. J Exp Med 2002;195: 1371-1377.

14 Lucas R, Juillard P, Decoster E, et al. Crucial role of tumor necrosis factor (TNF) receptor 2 and membranebound TNF in experimental cerebral malaria. Eur J Immunol 1997;27:1719-1725.

15 Gimenez F, Barraud DL, Fernandez C, et al. Tumor necrosis factor alpha in the pathogenesis of cerebral malaria. Cell Mol Life Sci 2003;60:1623-1635.

16 Nitcheu J, Bonduelle O, Combadiere C, et al. Perforindependent brain-infiltrating cytotoxic CD8+ T lymphocytes mediate experimental cerebral malaria pathogenesis. J Immunol 2003;170:2221-2228. 
17 Chang WL, Jones SP, Lefer DJ, et al. CD8(+)-T-cell depletion ameliorates circulatory shock in Plasmodium berghei-infected mice. Infect Immun 2001;69:7341-7348.

18 Belnoue E, Kayibanda M, Vigario AM, et al. On the pathogenic role of brain-sequestered alphabeta CD8+ T cells in experimental cerebral malaria. J Immunol 2002;169:6369-6375.

19 Nagase H, Woessner JF. Matrix metalloproteinases. J Biol Chem 1999;274:21491-21494.

20 Parks WC, Wilson CL, Lopez-Boado YS. Matrix metalloproteinases as modulators of inflammation and innate immunity. Nat Rev Immunol 2004;4: $617-629$.

21 Gursoy-Ozdemir Y, Qiu J, Matsuoka N, et al. Cortical spreading depression activates and upregulates MMP9. J Clin Invest 2004;113:1447-1455.

22 Mun-Bryce S, Rosenberg GA. Gelatinase B modulates selective opening of the blood-brain barrier during inflammation. Am J Physiol 1998;274:R1203-R1211.

23 Yong VW, Power C, Forsyth P, et al. Metalloproteinases in biology and pathology of the nervous system. Nat Rev Neurosci 2001;2:502-511.

24 Opdenakker G, Van den Steen PE, Van Damme J. Gelatinase B: a tuner and amplifier of immune functions. Trends Immunol 2001;22:571-579.

25 Van den Steen PE, Dubois B, Nelissen I, et al. Biochemistry and molecular biology of gelatinase B or matrix metalloproteinase-9 (MMP-9). Crit Rev Biochem Mol Biol 2002;37:375-536.

26 Asahi M, Asahi K, Jung JC, et al. Role for matrix metalloproteinase 9 after focal cerebral ischemia: effects of gene knockout and enzyme inhibition with BB-94. J Cereb Blood Flow Metab 2000;20:1681-1689.

27 Asahi M, Wang X, Mori T, et al. Effects of matrix metalloproteinase-9 gene knock-out on the proteolysis of blood-brain barrier and white matter components after cerebral ischemia. J Neurosci 2001;21:7724-7732.

28 Prato M, Giribaldi G, Polimeni M, et al. Phagocytosis of hemozoin enhances matrix metalloproteinase-9 activity and TNF-alpha production in human monocytes: role of matrix metalloproteinases in the pathogenesis of falciparum malaria. J Immunol 2005;175:6436-6442.

29 Gearing AJ, Beckett P, Christodoulou M, et al. Processing of tumour necrosis factor- $\alpha$ precursor by metalloproteinases. Nature 1994;370:555-557.

30 Gearing AJH, Beckett P, Christodoulou M, et al. Matrix metalloproteinases and processing of pro-TNF- $\alpha$. J Leukoc Biol 1995;57:774-777.

31 Black RA, Rauch CT, Kozlosky CJ, et al. A metalloproteinase disintegrin that releases tumour-necrosis factor-alpha from cells. Nature 1997;385:729-733.

32 Moss ML, Jin SL, Milla ME, et al. Cloning of a disintegrin metalloproteinase that processes precursor tumour-necrosis factor-alpha. Nature 1997;385: 733-736.

33 Sullivan AD, Ittarat I, Meshnick SR. Patterns of haemozoin accumulation in tissue. Parasitology 1996; 112(Part 3):285-294.

34 Pagenstecher A, Stalder AK, Campbell IL. RNAse protection assays for the simultaneous and semiquantitative analysis of multiple murine matrix metalloproteinase (MMP) and MMP inhibitor mRNAs. J Immunol Methods 1997;206:1-9.

35 Descamps FJ, Martens E, Opdenakker G. Analysis of gelatinases in complex biological fluids and tissue extracts. Lab Invest 2002;82:1607-1608.
36 Masure S, Billiau A, Van Damme J, et al. Human hepatoma cells produce an $85 \mathrm{kDa}$ gelatinase regulated by phorbol 12-myristate 13-acetate. Biochim Biophys Acta 1990;1054:317-325.

37 Pagenstecher A, Stalder AK, Kincaid CL, et al. Regulation of matrix metalloproteinases and their inhibitor genes in lipopolysaccharide-induced endotoxemia in mice. Am J Pathol 2000;157:197-210.

38 Oh LYS, Larsen PH, Krekoski CA, et al. Matrix metalloproteinase-9/gelatinase $B$ is required for process outgrowth by oligodendrocytes. J Neurosci 1999; 19:8464-8475.

39 Opdenakker G, Van den Steen PE, Dubois B, et al Gelatinase B functions as regulator and effector in leukocyte biology. J Leukocyte Biol 2001;69:851-859.

40 Dubois B, Masure S, Hurtenbach U, et al. Resistance of young gelatinase B-deficient mice to experimental autoimmune encephalomyelitis and necrotizing tail lesions. J Clin Invest 1999;104:1507-1515.

41 Dubois B, Starckx S, Pagenstecher A, et al. Gelatinase B deficiency protects against endotoxin shock. Eur J Immunol 2002;32:2163-2171.

42 Murphy G, Willenbrock F. Tissue inhibitors of matrix metalloendopeptidases. Methods Enzymol 1995;248: 496-510.

43 Amour A, Hutton M, Knauper V, et al. Inhibition of the metalloproteinase domain of mouse TACE. Ann NY Acad Sci 1999;878:728-731.

$44 \mathrm{Li}$ YY, Kadokami T, Wang $\mathrm{P}$, et al. MMP inhibition modulates TNF-alpha transgenic mouse phenotype early in the development of heart failure. Am J Physiol Heart Circ Physiol 2002;282:H983-H989.

45 D'Haese A, Wuyts A, Dillen C, et al. In vivo neutrophil recruitment by granulocyte chemotactic protein-2 is assisted by gelatinase B/MMP-9 in the mouse. J Interferon Cytokine Res 2000;20:667-674.

46 Kolaczkowska E, Scislowska-Czarnecka A, Chadzinska $\mathrm{M}$, et al. Enhanced early vascular permeability in gelatinase B (MMP-9)-deficient mice: putative contribution of COX-1-derived PGE2 of macrophage origin. J Leukoc Biol 2006;80:125-132.

47 Deininger $\mathrm{MH}$, Winkler S, Kremsner PG, et al. Angiogenic proteins in brains of patients who died with cerebral malaria. J Neuroimmunol 2003;142: 101-111.

48 Van Lint P, Wielockx B, Puimege L, et al. Resistance of collagenase-2 (matrix metalloproteinase-8)-deficient mice to TNF-induced lethal hepatitis. J Immunol 2005;175:7642-7649.

49 Wielockx B, Lannoy K, Shapiro SD, et al. Inhibition of matrix metalloproteinases blocks lethal hepatitis and apoptosis induced by tumor necrosis factor and allows safe antitumor therapy. Nat Med 2001;7:1202-1208.

50 Tan RJ, Fattman CL, Niehouse LM, et al. Matrix metalloproteinases promote inflammation and fibrosis in asbestos-induced Lung Injury in Mice. Am J Respir Cell Mol Biol 2006, in press [Epub ahead of print].

51 Lee MM, Yoon BJ, Osiewicz K, et al. Tissue inhibitor of metalloproteinase 1 regulates resistance to infection. Infect Immun 2005;73:661-665.

52 McClellan SA, Huang X, Barrett RP, et al. Matrix metalloproteinase- 9 amplifies the immune response to Pseudomonas aeruginosa corneal infection. Invest Ophthalmol Vis Sci 2006;47:256-264.

53 Turner GD, Morrison H, Jones M, et al. An immunohistochemical study of the pathology of fatal malaria. Evidence for widespread endothelial activation and a 
potential role for intercellular adhesion molecule-1 in cerebral sequestration. Am J Pathol 1994;145: 1057-1069.

54 Pilcher BK, Wang M, Qin X-J, et al. Role of matrix metalloproteinases and their inhibition in cutaneous wound healing and allergic contact hypersensitivity. Ann NY Acad Sci 1999;878:12-24.

55 Larsen PH, Wells JE, Stallcup WB, et al. Matrix metalloproteinase-9 facilitates remyelination in part by processing the inhibitory NG2 proteoglycan. J Neurosci 2003;23:11127-11135.

56 Powell WC, Fingleton B, Wilson CL, et al. The metalloproteinase matrilysin proteolytically generates active soluble Fas ligand and potentiates epithelial cell apoptosis. Curr Biol 1999;9:1441-1447.

57 Schönbeck U, Mach F, Libby P. Generation of biologically active IL- $1 \beta$ by matrix metalloproteinases: a novel caspase-1-independent pathway of IL-1 $\beta$ processing. J Immunol 1998;161:3340-3346.

58 Sheu BC, Hsu SM, Ho HN, et al. A novel role of metalloproteinase in cancer-mediated immunosuppression. Cancer Res 2001;61:237-242.

59 Van den Steen PE, Proost P, Wuyts A, et al. Neutrophil gelatinase $\mathrm{B}$ potentiates interleukin-8 tenfold by aminoterminal processing, whereas it degrades CTAP-III, PF-4, and GRO-alpha and leaves RANTES and MCP-2 intact. Blood 2000;96:2673-2681.

60 McQuibban GA, Gong JH, Tam EM, et al. Inflammation dampened by gelatinase A cleavage of monocyte chemoattractant protein-3. Science 2000;289:12021206.

61 Murata CE, Goldberg DE. Plasmodium falciparum falcilysin: a metalloprotease with dual specificity. J Biol Chem 2003;278:38022-38028. 